\title{
Static and modal analysis of a deep soil loosening machine
}

\author{
Gabriel Gheorghe ${ }^{1, *}$, Daniel Lates ${ }^{2}$, Catalin Pers $u^{1}$ and Marinela Mateescu ${ }^{1}$ \\ ${ }^{1}$ National Research -Development Institute for Machines and Installations Designed to Agriculture \\ and Food Industry, 6 Ion Ionescu de la Brad Blv., 013813 Bucharest, Sector 1, Romania \\ ${ }^{2}$ IRUM, 6 Axente Sever, 545300, Reghin, Mures, Romania
}

\begin{abstract}
The article will present a static analysis of the equipment in order to calculate the vector field distribution of the relative - resulting displacement in the structure, the Cauchy stress tensor and tensor fields distribution of the specific deformation in the same structure. This is done in order to improve the structure and highlight the most vulnerable points within an equipment depending on the way of working. After performing the static analysis, tensometric marks were mounted in the most vulnerable points to calculate the displacement of the material and to calculate the major forces that appeared in the structure during the field experiments. At the same time, the idea of the equipment prototype was to improve the equipment with vibrating elements on the working bodies of the body type in order to increase the degree of crushing and to reduce the advancing forces, respectively to reduce the fuel consumption. Therefore, a modal analysis was performed to calculate the vibrations that appeared in the structure in order not to resonate with the frequency of the motor mounted on the working member.
\end{abstract}

\section{Introduction}

The development of equipment for the preparation of the germination bed is a topical topic, and in this field there are several types of equipment for the preparation of the germination bed. [5] Most of the research was performed on equipment such as chisel / subsoiler, the research in the field was performed theoretically / laboratory / field. In all these works the same essential things are determined for a tillage machine the Cauchy stress tensor, and in other works the frequencies appearing in the structure are also investigated in order to determine the lifetime of the component elements within an equipment. [6-10] But testing a plow with a vibrating element mounted on each body has not been studied.

Due to the complexity of the designed equipment (fig.1) when it was subjected to analysis due to the lack of power of the computer, the analysis could not be performed, and it was simplified to perform the analysis only on the general framework.

\footnotetext{
* Corresponding author: gabrielvalentinghe@yahoo.com
} 


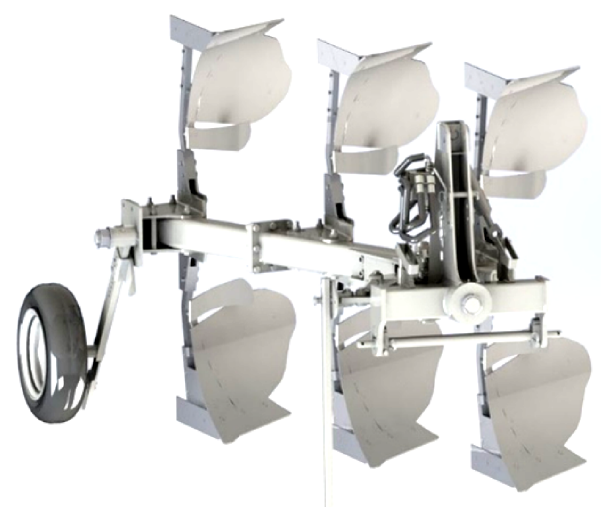

Fig.1. CAD model of agricultural reversible plow

\section{Materials and methods}

\subsection{Boundary conditions (Structure support)}

The structure is supported in three points by the system of connection to the tractor, figure 2. The connection to the tractor is done (exaggeratedly) by rigid fixing (annulment of all degrees of freedom on the contact surfaces between the tractor - plow connection elements).

Fig.2. Way of supporting the structure

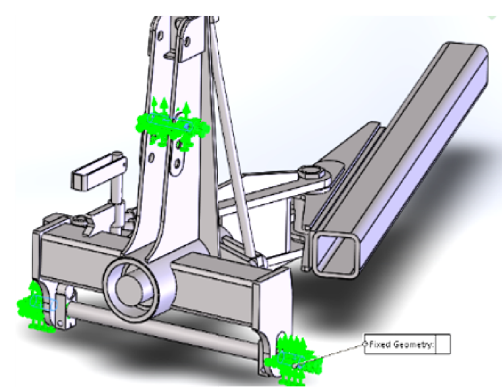

\subsection{Structure loading}

The loading of the structure will normally be done on the surface of the working organ in the opposite direction of advancing but taking into account that the framework is studied and not the working organs, because it is harder to replace than a working organ and much more expensive if it yields. . Therefore, a resistance force was applied resulting from the force applied on the three working organs and applied as a resistance force from the ground.

$$
F_{0}=k a_{0} b_{0}+\varepsilon a_{0} b_{0} v^{2},
$$

where index 0 sizes correspond to the working parts of the plow-body. In (1) $F_{0}$ is the resistance force of the soil to the action of the plow-body, $\mathrm{a}_{0}, \mathrm{~b}_{0}$, are the working depth and width of the respective area of the working part, and $\mathrm{k}_{0}, \varepsilon_{0}$, are the specific resistances to deformation of the soil and resistance coefficients to deformation of the soil due to the working speed.

The working speed was noted with $\mathrm{v}$. In the considered example we used the values: $\mathrm{a}_{0} \mathrm{~b}_{0}=0.39 \mathrm{~m}, \mathrm{k}=3500 \mathrm{~N} \cdot \mathrm{m}^{-1}, \varepsilon=2200 \mathrm{~kg} / \mathrm{m} 3, \mathrm{v}=5 \mathrm{~km} / \mathrm{h}$. The forces were applied to the 
structure according to the graphical representation in figure 3; a force on the working part of about $20000 \mathrm{~N}$ will result.

Also, within the analysis the mass $(m=600 \mathrm{~kg})$ of the rest of the structure was added in the opposite direction of the force of about $5886 \mathrm{~N}$.

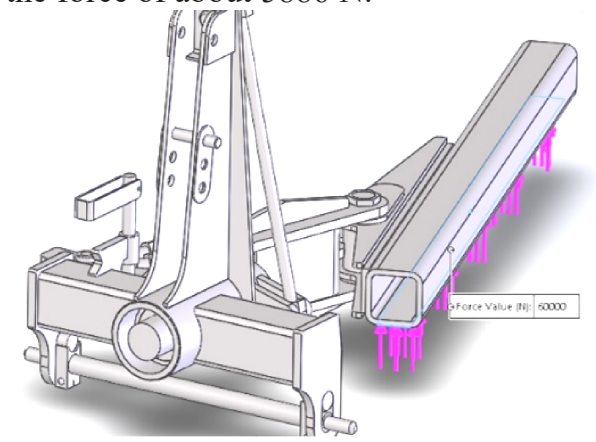

Fig.3. Way to apply loads (forces)

In addition to the force calculated using the formula, the traction force was determined also with the help of the strain gauges applied on the support for fixing the breast to the frame (Fig.4).

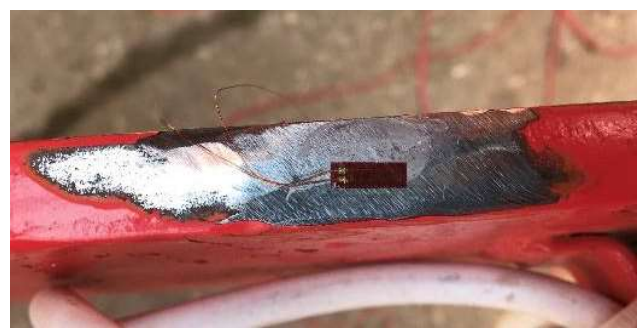

Fig.4. Attaching strain gauges to determine the traction force

This force was calculated under the field conditions and with the qualitative indices from table 1.

Table 1. Field conditions and qualitative indices

\begin{tabular}{|c|c|c|c|c|c|}
\hline \multicolumn{2}{|c|}{$\begin{array}{c}\text { Soil compaction test- } \\
\text { experimental plot }\end{array}$} & \multicolumn{2}{|c|}{$\begin{array}{c}\text { Soil } \\
\text { moisture }\end{array}$} & $\begin{array}{c}\text { Working } \\
\text { width } \\
\text { (cm) }\end{array}$ & $\begin{array}{c}\text { Working } \\
\text { depth } \\
\text { (cm) }\end{array}$ \\
\hline $\begin{array}{c}\text { Depth } \\
\text { (cm) }\end{array}$ & $\begin{array}{c}\text { Penetration } \\
\text { resistance, } \\
\text { (kPa) }\end{array}$ & $\begin{array}{c}\text { Depth, } \\
\text { (cm) }\end{array}$ & $\begin{array}{c}\text { Value } \\
\text { (\%) }\end{array}$ & 100 & 28 \\
\hline 0 & 386 & $0-10$ & 15,5 & 105 & 31 \\
\hline 2,5 & 537 & $10-20$ & 25,7 & 97 & 33 \\
\hline 5 & 596 & $20-30$ & 28,4 & 101 & 32 \\
\hline 7,5 & 737 & & & 93 & 30 \\
\hline
\end{tabular}




\begin{tabular}{|c|c|c|c|}
\hline 10 & 772 & 98 & 31 \\
\hline 12,5 & 877 & 100 & 30 \\
\hline 15 & 1123 & 102 & 34 \\
\hline 17,5 & 1193 & 96 & 33 \\
\hline 20 & 1404 & 105 & 35 \\
\hline 22,5 & 1650 & & \\
\hline 25 & 2071 \\
& 2120 & & \\
\hline
\end{tabular}

Figure 5 shows the diagram of the traction force resulted on the experimental plot by the aggregate AGRICULTURAL PLOW FOR $70 \mathrm{KW}$ AGRICULTURAL TRACTORS + TAGRO 102 tractor.

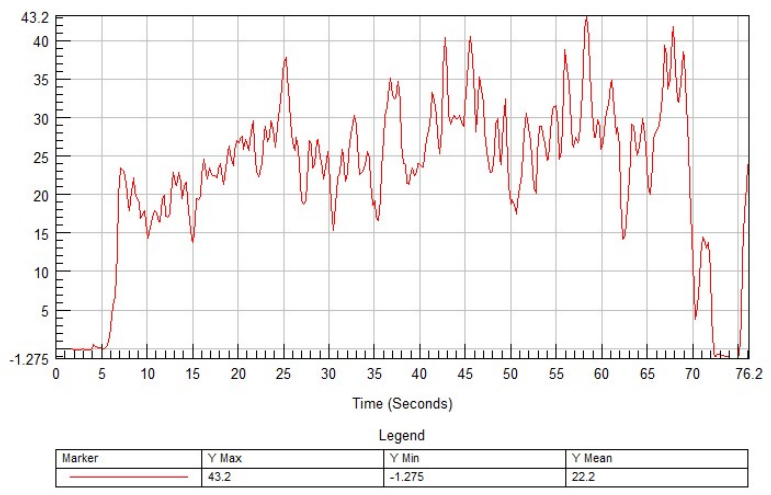

Fig. 5. Average traction force $(\mathrm{kN})$

- Traction force of reversible plow with 3 plow-bodies IRUM Reghin

For performing the linear elastic static analysis, the global contact command was applied. This condition applied by the finite element analysis operator eliminates any kind of distances, creating stress conditions corresponding to a structure more rigid than the real one. Thus, the stresses will be higher than the real ones, and the relative displacements (deformations) are expected to have lower values than the real ones. The discretization of the structure can be seen in figure 6 . 


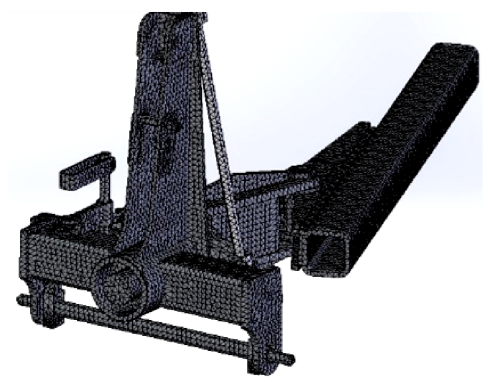

Fig.6. Structure discretization: projection of the finite elements on the boundary of the structure

The material that will be used in the structure analysis is the S275JR material, which has certain properties presented in figure 7.

\begin{tabular}{|l|l|l|}
\hline Property & Value & Units \\
\hline Elastic modulus & $2.100000031 \mathrm{e}+011$ & $\mathrm{~N} / \mathrm{m}^{\wedge} 2$ \\
\hline Poisson's ratio & 0.28 & $\mathrm{~N} / \mathrm{A}$ \\
\hline Shear modulus & $7.9 \mathrm{e}+010$ & $\mathrm{~N} / \mathrm{m}^{\wedge} 2$ \\
\hline Mass density & 7800 & $\mathrm{~kg} / \mathrm{m}^{\wedge} 3$ \\
\hline Tensile strength & 410000000 & $\mathrm{~N} / \mathrm{m}^{\wedge} 2$ \\
\hline Compressive Strength in X & & $\mathrm{N} / \mathrm{m}^{\wedge} 2$ \\
\hline Yield strength & 275000000 & $\mathrm{~N} / \mathrm{m}^{\wedge} 2$ \\
\hline Thermal expansion coefficient & $1.1 \mathrm{e}-005$ & $/ \mathrm{K}$ \\
\hline Thermal conductivity & 14 & $\mathrm{~W} /(\mathrm{m} \cdot \mathrm{K})$ \\
\hline Specific heat & 440 & $\mathrm{~J} /(\mathrm{kg} \cdot \mathrm{K})$ \\
\hline Material namninn Ratin & & $\mathrm{N} / \mathrm{A}$
\end{tabular}

Fig.7. Properties of material S275JR.

\section{Results and discussion}

The first result of the structural analysis are the reactions that appeared in the structure as a result of the applied force, and the other results are displacement in the structure, the Cauchy stress tensor and tensor fields distribution of the specific deformation, as well the safety factor.[1] Table 2 shows the values of the resulting forces' components, which are also found in the values of the reaction forces (in the three support zones).

Table 2. Values of the resulting forces components

\begin{tabular}{|c|c|c|c|c|}
\hline Components & $\mathrm{X}$ & $\mathrm{Y}$ & $\mathrm{Z}$ & Resultant \\
\hline Reaction force (N) & -3.01367 & -54110.8 & -2.17969 & 54110.8 \\
\hline
\end{tabular}
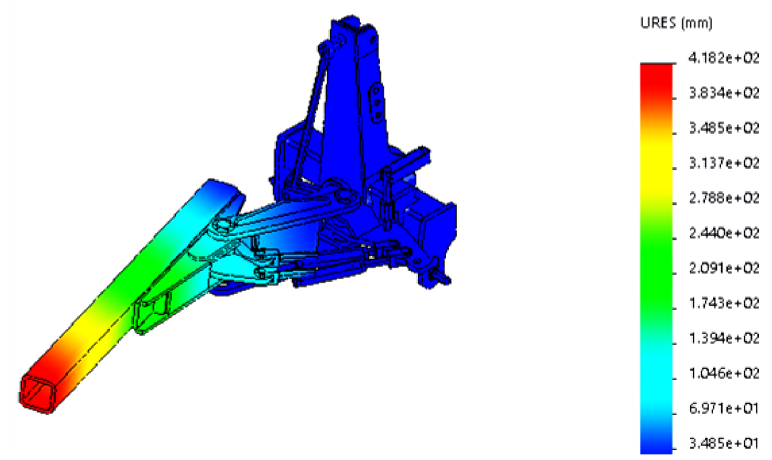

Fig.8. Distribution of the values of the relative resultant displacement field on the structure boundary 
The distribution maps of the values of the relative resultant displacement field on the structure boundary are graphically shown in Figure 8. It is noted that the maximum value is located in the back of the structure. This maximum value can be exceeded if clearance of the structure and system connecting the plow and the tractor is taken into account. The increase of the displacement, under the conditions of the considered stress, with the admission of the clearances, contributes to the relaxation of the structure and implicitly the increase of the safety factor. However, exaggerated clearances generally lead to possible wear.
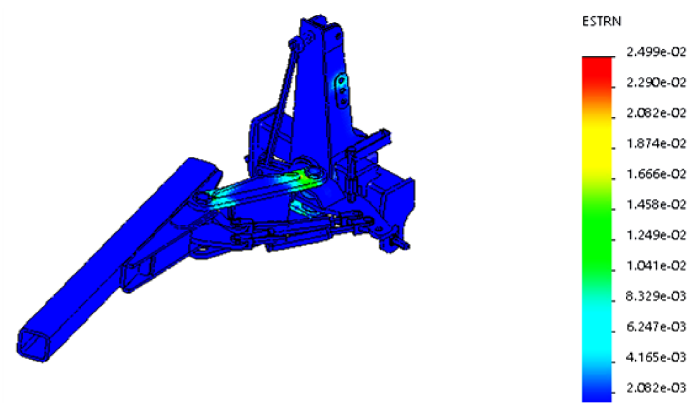

Fig.9. Distribution of total specific deformation field values on the structure boundary.

The distribution of the total specific deformation values is graphically represented by the colour map in Figure 9. Due to the fact that we work in the elastic-linear domain, the maximum tension will be located in the same area as the maximum specific deformation. The maximum equivalent stress is represented graphically in the same way, in figure 10, where it can be seen that very high stresses appear in the middle piece, being a very stressed piece, even if in the design and execution phase of the experimental model a reinforcement was added to eliminate these high stresses.
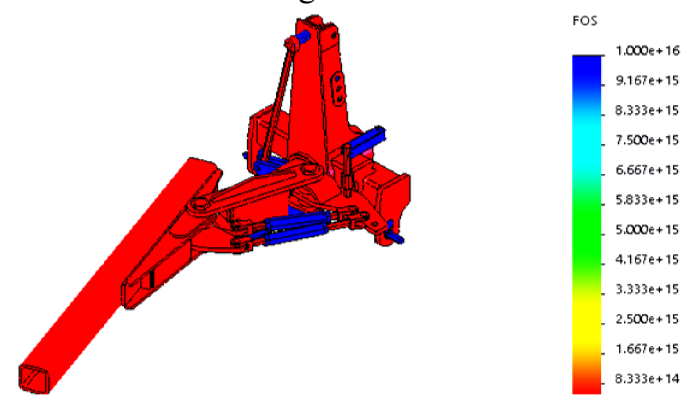

Fig.10. Distribution of the safety factor on the structure boundary

The safety factor is 8.33 . For agricultural equipment that work with soil in order to prepare the germination bed, the value of the safety coefficient is between 1.8 and 2.2. The equipment can be oversized or has been designed and thinking to withstand certain accidents during work. Considering the maximum values of the equivalent stress, there is no danger for the structure material to cease.

Due to this very high coefficient, we'll perform an optimization regarding the material used; we'll run the simulation with a material that is weaker in terms of properties (fig. 11), but also cheaper, to reach a coefficient between $1.8-2.2$. 

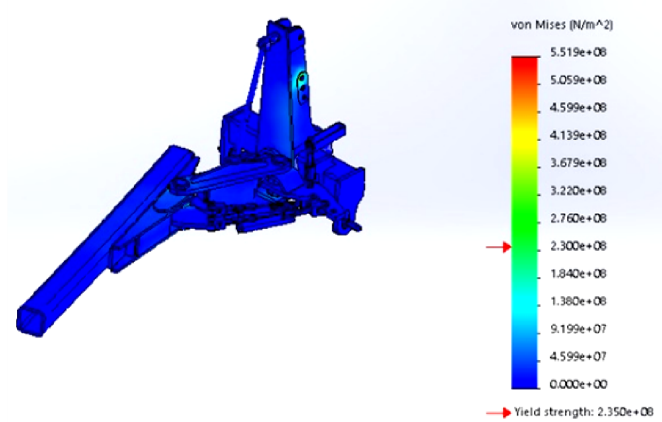

Fig.11. Representation of the equivalent stress distribution on the structure boundary for S235JR material

Because of this, you can no longer talk about observations on the safety factor since it is below 1 in that area. Due to the transformation of the experimental model into a prototype and the addition of the vibrating element to optimize the structure and avoid its resonance, a modal analysis of the basic structure of a plow was also performed. The analysed structure is a modern plow structure, with load bearing structure consisting of plates and pipes. Modal analysis or frequency analysis for this structure, aims to determine its own frequencies and to identify the components with maximum amplitude on each of the basic own frequencies.[4] The intense interaction with the tractor can induce the vibrations of the structure analysed into the resistance structure of the tractor, possibly retransmitted then through suspension to the tractor driver. The consequences can be estimated using the knowledge about vibrations effects on the human body. [2]

Starting from the findings of the modal analysis, improvements of the system can be made by small modifications of some components of the assembly or by modifying some adjustments allowed in operation or in the operating regime. Finally, we mention that frequency analysis is the first step in dynamic analysis, because the latter uses the first results to calculate the structure response to various time-varying loads. The relative displacements by directions and resultants in the structure, for each vibration mode, are given separately. Also, the colour maps of the relative displacements field are given, by component or resultant.[3] Table 3 shows, from the report of the SOLIDWORKS program, with the help of which (using the SIMULATION module) a frequency analysis was made, a list of the first five own frequencies, corresponding to five vibration modes, each with the normalized displacements on the three directions.

Table 3. First five own frequencies

\begin{tabular}{|c|c|c|c|c|c|}
\hline $\begin{array}{c}\text { Mode } \\
\text { number }\end{array}$ & $\begin{array}{c}\text { Frequency } \\
\text { (Hertz) }\end{array}$ & $\begin{array}{c}\text { Frequency } \\
\text { (rad/s) }\end{array}$ & Direction X & Direction Y & Direction Z \\
\hline $\mathbf{1}$ & 16.128 & 101.33 & $\begin{array}{c}3.6315 \mathrm{e}- \\
005\end{array}$ & 0.00015334 & $\begin{array}{c}4.8081 \mathrm{e}- \\
005\end{array}$ \\
\hline $\mathbf{2}$ & 18.625 & 117.03 & 0.021966 & 0.0088722 & $\begin{array}{c}4.2245 \mathrm{e}- \\
008\end{array}$ \\
\hline $\mathbf{3}$ & 58.632 & 368.4 & 0.030122 & 0.049132 & $1.301 \mathrm{e}-006$ \\
\hline $\mathbf{4}$ & 67.257 & 422.59 & 0.00032949 & 0.00028952 & 0.00022521 \\
\hline $\mathbf{5}$ & 100.68 & 632.59 & 0.00051331 & 0.00025398 & $\begin{array}{c}3.3279 \mathrm{e}- \\
005\end{array}$ \\
\hline
\end{tabular}


Another way to give these results is shown in table 4, where the own frequencies and amplitude maps are given on the deformed form of the structure in the vibration modes corresponding to that frequency.

Table 4. Frequencies and amplitude maps

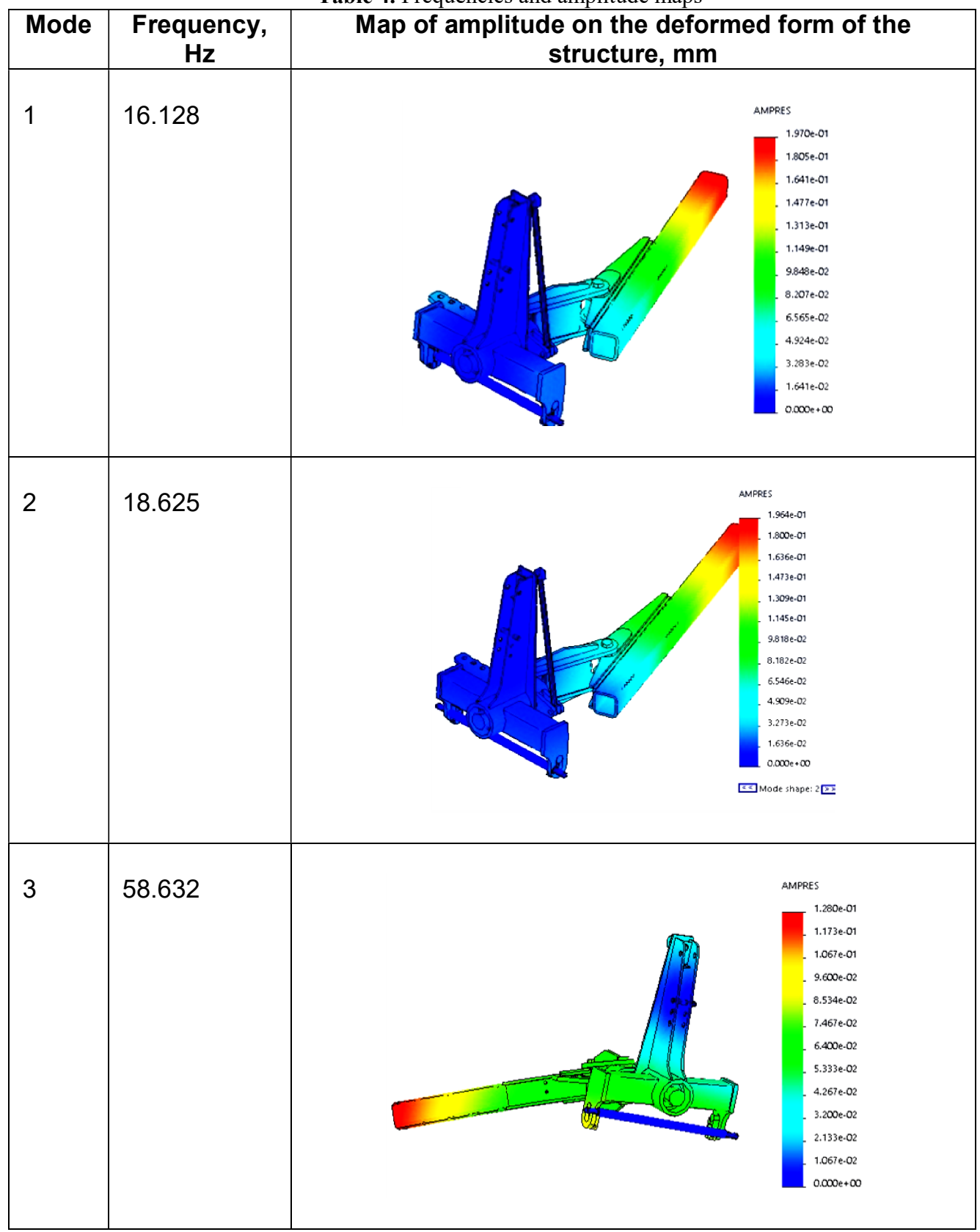




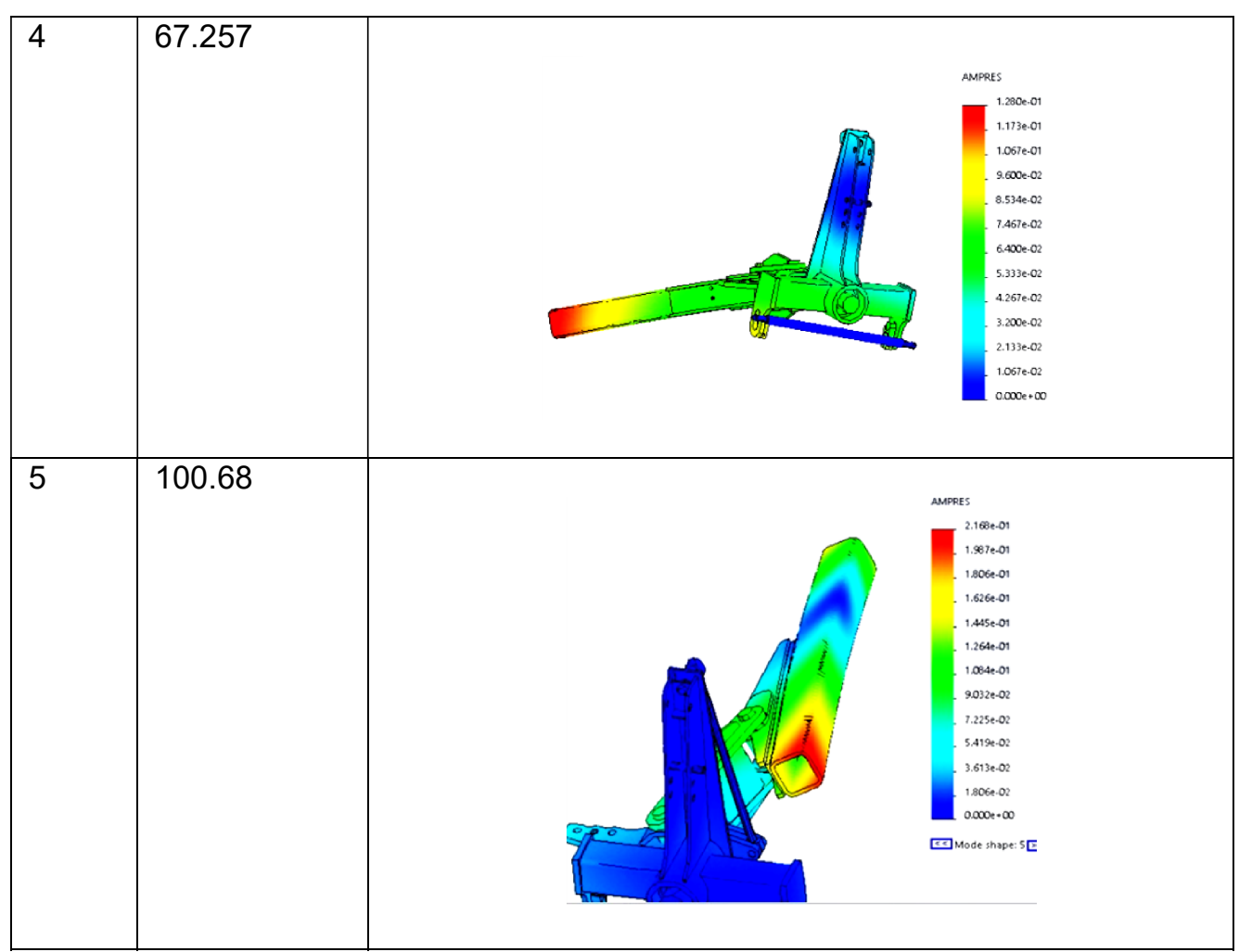

\section{Conclusions}

1. Finally, own spectrum is also useful in identifying the source of parasitic own oscillations. Once this oscillation is identified, the source is usually looked for in the working regime: either accidental phenomena (different deficiencies of the aggregate) or, in the existence on the analysed structure of some working devices (pumps for spraying machines, mechanical cutting devices, etc.) that work on the structure's own frequencies or on very close frequencies. In these cases, changes of the working regime of the devices are made or the isolation of these devices from the rest of the structure is improved.

2. The usefulness of this analysis is proven especially in the test phase and even in the first stages of operation, when the working regime of a product of the type analysed must be improved.

3. The frequency of the engine added for introducing vibrations into the working part is not among the five own frequencies calculated. The engine having a speed of 3000 $\mathrm{rpm}$, an engine frequency of $1.21 \mathrm{~Hz}$ will result, which is very far from the own frequencies of the equipment structure.

This work was supported by the European Regional Development Fund under the Competitiveness Operational Program 2014-2020, Project "Rapid knowledge transfer and technicalscientific support in developing competitive products and technologies in enterprises specific to the field of bioeconomy and the production of bioresources" - contract 80/08.09.2016, MySMIS 105551, subsidiary contract 916/22.08.2017 "AGRICULTURAL PLOW FOR 70 KW AGRICULTURAL TRACTORS” („PLUG AGRICOL PENTRU TRACTOARE AGRICOLE CU PUTERE DE $70 \mathrm{kW”)}$ and by a grant of the Romanian Research and Innovation Ministry, through Programme 1Development of the national research-development system, subprogramme 1.2-Institutional performance-Projects for financing excellence in RDI, contract no. 16PFE. 


\section{References}

1. G. Gheorghe, C. Persu, I.Gageanu, D.Cujbescu. "Structural and modal analysis in SolidWorks of basic structure of equipment to prepare germinative bed in strips", Latvia University of Life Sciences and Technologies, 2018

2. M. Matache, Gh. Voicu, P. Cardei, V. Vladut, C. Persu, I. Voicea, Accelerated test of MAS 65 deep soil loosening machine frame, Proceedings of the 43rd international symposium on agricultural engineering, Opatija, Croatia, 2015.

3. A David., Gh. Voicu, E. Marin, M. Dutu, G. Gheorghe, Experimental researches on working qualitative indexes of a deep loosening equipment, INMATEH-Agricultural Engineering, vol 46, pp 5-12, no. 2/2015

4. M.FUTATSUKA, S. MAEDA, T. INAOKA, M. NAGANO, M. SHONO, T. MIYAKITA, Whole-Body Vibration and Health Effects in the Agricultural Machinery Drivers, Industrial Health Vol. 36 (1998) No. 2 P 127-132.

5. Croitoru Şt., Marin E., Bădescu M., Manea D., Vlăduţ V., Ungureanu N., Manea D., Boruz S., Matei Gh. - Researches regarding the minimum work for improving soil fertility by deep loosening, PROCEEDINGS OF THE 43 INTERNATIONAL SYMPOSIUM ON AGRICULTURAL ENGINEERING "Actual Tasks on Agricultural Engineering", pp. 165-176, 2015, Opatija - Croaţia;

6. Croitoru Şt., Vlăduţ V., Voicea I., Gheorghe Gh., Marin E., Vlăduţoiu L., Moise V., Boruz S., Pruteanu A., Andrei S., Păunescu D.- Structural and kinematic analysis of the mechanism for arable deep soil loosening, PROCEEDINGS OF THE 45 INTERNATIONAL SYMPOSIUM ON AGRICULTURAL ENGINEERING "Actual Tasks on Agricultural Engineering", pp. 207-216, 2017, Opatija - Croaţia;

7. Matache M., Voicu Gh., Cardei P., Vladut V., Persu C., Voicea I. - Accelerated test of MAS 65 deep soil loosening machine frame, PROCEEDINGS OF THE 43 INTERNATIONAL SYMPOSIUM ON AGRICULTURAL ENGINEERING "Actual Tasks on Agricultural Engineering", pp. 131-140, 2015, Opatija - Croaţia;

8. Vlăduţ V., Gheorghe G., Marin E., Biriş S.Șt., Paraschiv G., Cujbescu D., Ungureanu N., Găgeanu I., Moise V., Boruz S. - Kinetostatic analysis of the mechanism of deep loosening system of arable soil, PROCEEDINGS OF THE 45 INTERNATIONAL SYMPOSIUM ON AGRICULTURAL ENGINEERING "Actual Tasks on Agricultural Engineering", pp. 217-228, 2017, Opatija - Croaţia;

9. Vlăduţoiu L., Cârdei P., Vlăduţ V., Fechete L. - Modern trends in designing and selecting the machine / equipment for soil deep tillage, 16th International Scientific Conference "ENGINEERING FOR RURAL DEVELOPMENT", pp. 1415-1420, Jelgava, Latvia;

10. Vlăduţ V., Croitoru Şt., Constantin N., Paraschiv G., Voicu Gh., Biriş S., Bungescu S., Caba I., Ludig M., Atanasov At. - Soil tillage optimization by un-compaction and aeration of deficient deep soils, 4rd International Conference "Research People and Actual Tasks on Multidisciplinary Sciences", pp. 324-330, Lozenec, Bulgaria; 